\title{
The Effects of ATO on Mitochondria Apoptosis Pathway Genes Expression in APL Cell Line
}

\author{
Maede Sharifizadeh $^{1}$, Kimia Davarian ${ }^{3}$, Mehrdad Hashemi ${ }^{1}$, Majid Momeni ${ }^{2}$, \\ Kamran Ali Moghdam², Ardeshir Ghavamzadeh², Hamidollah Ghafari², Abolfazl \\ Movafagh $^{3}$
}

${ }^{1}$ Department of Molecular Genetics, Tehran Medical Sciences Branch, Islamic Azad University, Tehran Iran. ${ }^{2}$ Blood, Oncology, and Basic Cells Research Center, Shariati Hospital, Tehran University of Medical Sciences, Tehran Iran. ${ }^{3}$ Department of Medical Genetics, Cancer Research Center, Shohada Referral Hospital, School of Medicine, Shahid Beheshti University of Medical Sciences, Tehran, Iran.

\begin{abstract}
Purpose and Background: Acute promyelocystic leukemia is the most malignant acute leukemia that leads to death in few weeks. It constitutes $10-15 \%$ of acute myelocystic leukemia. Arsenic trioxide, as a single agent factor, is known as the best treatment for acute promyelocystic leukemia, which mainly functions by inducing apoptosis. However, there is no clear image of the mechanism through which apoptosis is induced and how the genes expression is deeply affected. Thus, the present study is an attempt to examine the effect of the agent on expression of the genes dealing with the cancer. Methodology: The study was carried out as an analytical work. To find out about the mechanisms effective on inducing apoptosis, cell line NB4 were cultured with $0.5 \mu \mathrm{M}, 1 \mu \mathrm{M}$, and $2 \mu \mathrm{M}$ arsenic trioxide and their RNA was extracted after $12 \mathrm{hrs}, 24 \mathrm{hrs}$, $28 \mathrm{hrs}$, and $72 \mathrm{hrs}$. Following cDNA synthesis, apoptosis genes expression at mitochondria pathway including caspase 3, Mcl-1, and Bcl-2 were examined using Real-Time PCR. The data was analyzed using t-test and variance analysis in Excel. Findings: It was found that arsenic caused apoptosis was featured with decrease of mRNA expression of Bcl-2 anti-apoptotic. However, expression of caspase 3 and Mcl-1 genes remained unchanged after culturing by arsenic. Conclusion: The results showed that changes in Bcl-2 gene expression can be considered as a mechanism of apoptosis caused by arsenic, while caspase 3 and Mcl-1 genes had no effect on the mechanism.
\end{abstract}

Keywords: Acute promyelocystic leukemia- arsenic trioxide- apoptosis, caspase 3- bcl-2 genes

Asian Pac J Cancer Biol, 1 (2), 37-42

\section{Introduction}

Acute promyelocystic leukemia (APL) is a blood cancer caused by defected growth of myeloid line white blood cells and aggregation of immature cells known as promyelocyte. Based on FBA classification (French-American-British), APL is a type of acute myelocytic leukemia AML (M3) and it was found by Lief Hillestad (1957) as an independent disease. APL represents $10-15 \%$ of AML and it mostly occurs at age range $40-50$ [1-2].

The main cause of ALP (more than 95\%) is a translocation between chromosomes 15 and 17. Breakage in chromosome 15 happens in promyelocystic leukemia
Submission Date: 03/13/2016 Acceptance Date: 05/25/2016

(PML), which codes a suppressor transcription factor. In chromosome 17 , breakage happens in retinoic acid receptor alpha (RAR $\alpha$ ) that controls the differentiation. The outcome of this translocation is a chimeric protein that prevents maturation of the myeloidic cells at promyelocystic stage and disturbs final differentiation of the cell [3-4].

APL is an invasive disease with abrupt onset. High risk of death in short-term (10-20\%) and notable potential of curing the disease (more than $80 \%$ ) highlight the necessity of timely diagnosis and initiation of intervention short after [5]. Out of 946 cases of hematopoietic system cancers in women in 2004, 21 cases were APL $(2.22 \%)$ so that the cancer is the 8 th

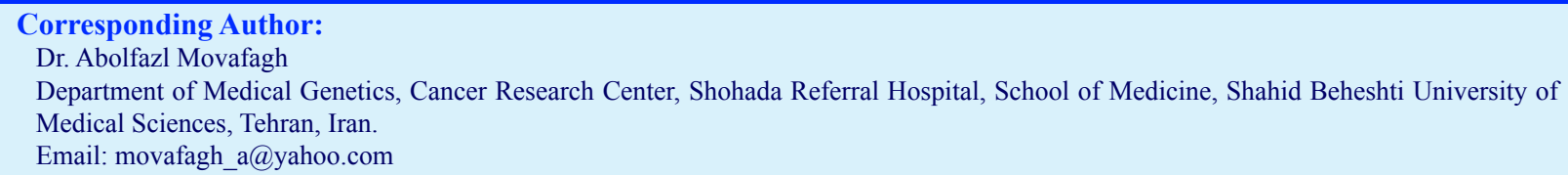


prevalent hematopoietic system cancer in women. As to men, out of 1549 cases of hematopoietic system cancers in 2004, 21 cases were APL (1.36\%), which place it at 7th ranking [6-7].

APL is in unique position to connect basic sciences and medicine with a notable role in development of novel treatments such as differentiation therapy. APL treatment is different from those of AML. Today, most of APL patients are treated by all-trans retinoic acid (ATRA), which activates retinoic acid receptors and differentiates promyelocytes. However, recurrent and development of resistance to treatment are the main problems with APL [8]. Thereby, it is necessary to surveys the new medicines for APL. ATO is one of the single agent factors (with no need to ATRA and other chemotherapy drugs) and it can induce complete remission (CR) in APL patients [9]. Arsenic was very effective in the 1990s to treat the recurred disease [10]. Low concentration ATO $(0.1-0.5 \mu \mathrm{M})$ incudes differentiation in cancerous promyelocyte through decomposing fusion protein PML-RAR; while high concentration ATO $(0.5-2 \mu \mathrm{M})$ targets promyelocyte apoptosis pathway and other cancerous cells through a variety of mechanisms. Apoptosis happens due to a genetic program in cells that leads to removal of and disruption of hemostasis and causes many malignant outcomes including APL [11-12].

Not all the mechanisms in charge of inducing apoptosis by arsenic are known to us, however, the main role of arsenic in inducing apoptosis is to target internal pathway of apoptosis or mitochondria pathway [11]. In light of this and to have better picture of arsenic function mechanism, expressions of several key genes (i.e. Mcl-1, Bcl-2, and Caspase3) in mitochondria pathway before and after treating cells by arsenic were examined

\section{Materials and Methods}

\section{Cell culture}

An analytical study was carried out. NB4 cell line with $\mathrm{t}(15,17)$ translocation were procured in vial from cell bank of Iran Pasteur Institute. The cells were cultured in RPMI-1640 (with L-glutamine) containing 10\% fetal bovine serum (FBS), 1\% antibiotics (penicillin and streptomycin) in incubator $\left(37^{\circ} \mathrm{C}\right.$ and $\left.5 \% \mathrm{CO}_{2}\right)$.

\section{Pharmaceutical care}

Arsenic ampoules (5000 $\mu \mathrm{M}$ - Sinadarou Tehran) were used for pharmaceutical care. To determine optimum effects of the medicine, dosage and time were examined as the two variables. Cancerous cells were treated by ATO $0.5 \mu \mathrm{M}, 1 \mu \mathrm{M}$ and $2 \mu \mathrm{M}$ and RNA was measured after 12 , 24,48 , and $72 \mathrm{hrs}$. Pharmacokinetic surveys showed that the used concentrations of ATO were equal with $0.15 \mathrm{mg} /$ $\mathrm{kg}$ mass weight of arsenic administered to patients, which caused a peak of ATO 5.5-7.5 $\mu \mathrm{M}$ immediately after the administration, which then rapidly returned to $1-2 \mu \mathrm{M}$ and ATM therapeutic range [13, 14].

\section{RNA extraction and $c D N A$ synthesis}

RNA extraction was done using commercial mini kits
RNeasy (Germany, Chiagen). Total RNA was checked by agarose gel containing ethidium bromide and observing $18 \mathrm{~s}$ and $28 \mathrm{~s}$ banks at 800 and 1,500 open pair positions of ribosomal RNA. Value and concentration of RNA were measured using optical density (OD) at 260 and 280nm.

To produce cDNA with constant concentration, $1 \mu \mathrm{g}$ of each RNA sample was inverse transcribed using PrimeScript $^{\mathrm{TM}}$ RT reagent (Takara Inc.).

\section{Real-Time PCR}

Real-time PCR was done using SYBR $®$ Green Premix EX Taq $^{\text {TM }}$ kit (Takara Inc.) and light cycler (Rovosh). The reactions were performed as Hot start PCR to avoid nonspecific proliferation and formation of dimmer initiator before the cycles begins. Real-Time PCR was a relative quantification where the target gen was compared with a housekeeping gene (HPRT) (Table 1). Thermal cycle was featured with one stage of enzyme activation for $30 \mathrm{~s}$ at $95^{\circ} \mathrm{C}$ that was followed with 45 cycles of denaturation $\left(5 \mathrm{~S} ; 60^{\circ} \mathrm{C}\right)$ and a mixed annealing/extension stage $(20 \mathrm{~s}$; $60^{\circ} \mathrm{C}$ ). Afterward, melting curve was executed to ensure specific proliferation of target DNA string.

The experiment was repeated for three samples for each dosage and time and variations were measured by calculating mean and standard deviation. Target gene expression relative to reference gene was obtained by $2^{-\Delta \Delta \mathrm{Ct}}$; while the data was analyzed using t-test and variance analysis in Excel $(\mathrm{P}<0.05)$.

\section{Results}

\section{Variation in Bcl-2 expression}

The results about Bcl-2 gene were obtained using Real-time PCR for 48hrs dose-dependent cultured cDNA cells and $2 \mu \mathrm{M}$ time-dependent cultured cDNA cells. Crossing point (CP) reading by light cycler are illustrated in diagrams 1 and 2. Clearly, Bcl-2 expression after treating the cells by ATO shows a considerable decrease comparing with control samples (zero sample) both in dose-dependent and time-dependent treatments.

\section{Variation in Caspase 3 expression}

To examine Caspase 3 expression, Real-time PCR was performed on dose-dependent cDNAs (48hrs). The results of $\mathrm{Cp}$ values analyses are illustrated in diagram 3. Afterward, Real-time PCR was performed on time-dependent cDNAs $(2 \mu \mathrm{M})$ (Diagram 4). Clearly and

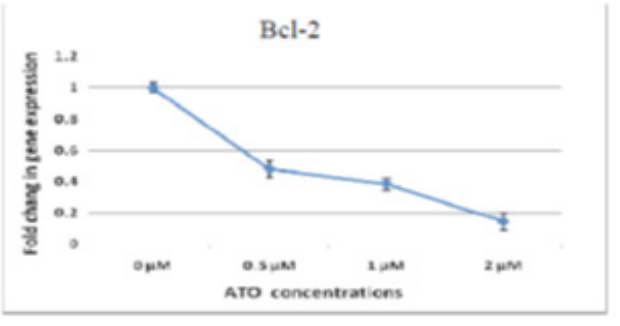

Diagram 1. Changes of Dose-Dependent Bcl-2 Expression in Nb4 Cells Treated by Different Dosages of Arsenic in $48 \mathrm{hrs}$. 


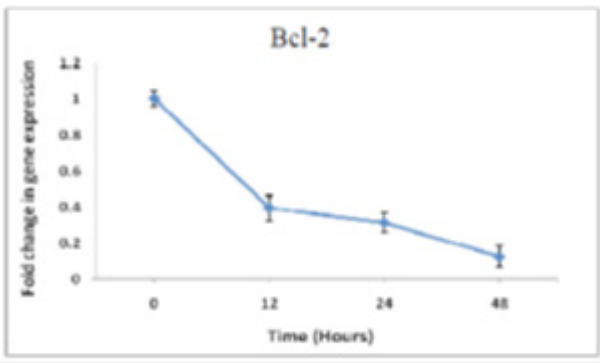

Diagram 2. Changes in Time-Dependent Bcl-2 Expression in Cells Treated by ATO $(2 \mu \mathrm{m})$

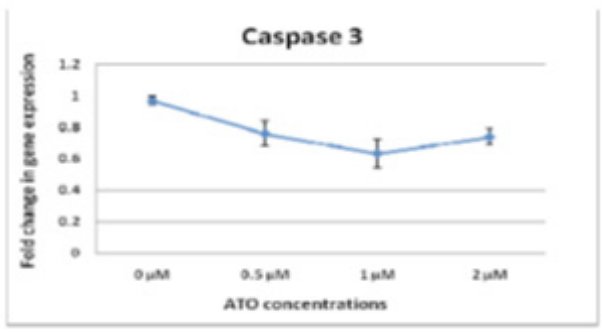

Diagram 3. Caspas3 Expression- 48hrs After Being Dose-Dependent Treated by ATO, the Decrease in the Expression is Not Considerable Comparing with the Control Samples

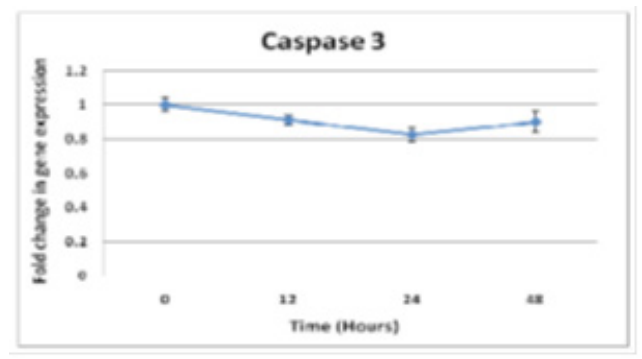

Diagram 4. Caspase3 Expression in NB4 Cells Treated By Arsenic $(2 \mu \mathrm{m})$ at Different Treatment Times Show No Change in Gene Expression

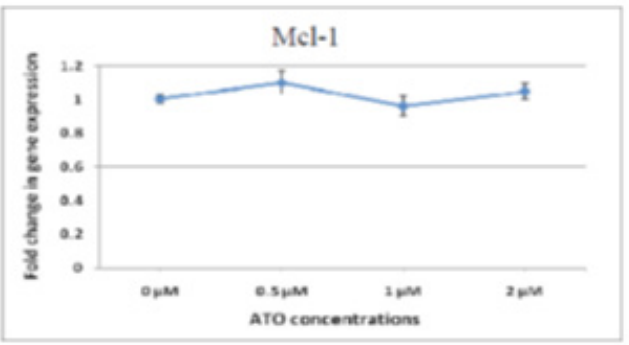

Diagram 5. Relative Expression of Mcl-1 in NB4 Cells Under Dose-Dependent Pharmaceutical Treatment (48hrs) Shows no Considerable Changes Comparing with the Control Samples

Table 1. Nucleotide Sequence of the Initiators Used in Real-Time PCR

\begin{tabular}{lll}
\hline Gene symbol & Progressive initiator & Invers initiator \\
\hline HPRT & TGGACAGGACTGAACGTCTTG & CCAGCAGGTCAGCAAAGAATTTA \\
Bcl-2 & GGGGAGGATTGTGGCCTTC & CAGGGCGATGTTGTCCACC \\
Casp3 & ATGGAAGCGAATCAATGGACT & CTGTACCAGACCGAGATGTCA \\
Mcl-1 & GTGCCTTTGTGGCTAAACACT & AGTCCCGTTTTGTCCTTACGA \\
\hline
\end{tabular}

comparing with control treatment (sample zero), caspase 2 expression does not change after treating the cells by ATO both in dose-dependent and time-dependent cultures.

\section{Variation in Mcl-1 expression}

Given that most of the studies on decrease of Mcl-1 along with apoptosis have focused on protein level and that it is not clear if the decrease in Mcl-1 protein is due to decrease in mRNA level through transcription or due to decrease in protein level and suppression of translation, in this study, changes in Mcl-1 gene expression were examined using Real-time method in APL cells for the first time. As illustrated (diagram 5) Mcl-1 expression after administering the medicine does not change considerably comparing with control sample.

\section{Discussion}

Bcl-2 expression in NB4 cells treated by ATO decreased in both dose-dependent and time-dependent cultures. Therefore, one of the key mechanisms of ATO is initiation of apoptosis mitochondria pathway. However, the results showed that expression of capsase 3 and Mcl-1 did not changed after treating cancerous cells by ATO.

Since the first observation of the relationship between arsenic and skin cancer in the 1820s, arsenic combinations have treated as a potential peripheral carcinogens and also mutagen for skin and liver [15-16]. However, specific concentration of some of arsenic combinations (e.g. ATO) is advantageous for human body physiology such as hematopoiesis stimulation. Using arsenic combinations as medicine has a long history in Chinese traditional medicine [17-18]. Arsenic trioxide is an inorganic compound with three valance with proven therapeutic effects on APL disease [19]. Probably, APL is the first acute leukemia that is curable through developing therapeutic and pharmaceutical solutions [20].

PML-RAR $\alpha$ fusion in APL cells interacts with transcription factors that control genes expression and induces post-transcriptional effects [21]. The results showed that ATO can reverse the transcription suppression and change genes expression in cancerous cells. Thereby, ATO targets PML-RAR $\alpha$ fusion and influences regulator transcription factors. Despite other studies on anticancer effects of ATO, we do not know what the exact molecular mechanisms of the medicine are. Because of this, apoptosis induce mechanism was examined in this paper.

Lee et al. (2000) showed that ATO causes phospho-acetylation histone of $\mathrm{H} 3$ in chromatin in locus of caspase10. This phenomenon induces caspase 10 
expression and activation in APL cells, which results in activation of caspases $3 \& 8$ and apoptosis [22]. Jang Wook et al. (2001) reported that ATO induces its growth suppression effect through changes in expression or activation of several key proteins that regulate $\mathrm{G} 2 / \mathrm{M}$. Arsenic increases CyclinB1 and activates cdc2/cycline B1 Kinase and phosphorylation of Bcl-2, which is coincident with activation of caspases $3 \& 7$ in mitosis cells. They concluded that an apoptosis induce mechanisms by arsenic might be due to cell cycle pause [23]. These reports and other studies indicate activation of caspase 3 due to ATO. One common feature of these works is that they all have focused on protein of the gene [16-24]. Here, caspase 3 expression at gene level was examined and it was observed that ATO had no effect on the expression of caspase 3 . Since the gene is an essential element for apoptosis, one can conclude that ATO influences caspases at single posttranslation level and this regulating effect ensures that caspases can be activated rapidly and induce apoptosis when it is needed.

The role of Mcl-1 protein in facilitating apoptosis by ATO in APL cancerous cells is not known yet. Like other members of Bcl-2, Mcl-1 relies on interaction with other proteins to regulate apoptosis [25]. We observed no changes in $\mathrm{MCl}-1$ gene expression along with apoptosis induce. One explanation for this is that $\mathrm{Bcl}-2$ proteins are regulated both at transcription stage and the next stages. Few amino acids between $\mathrm{BH} 3$ and $\mathrm{BH} 4$ domains in Mcl-1 protein are targeted by post-translation changes and ubiquitination. These post-translation changes determine stability of mcl-1 [26].

Nijhavan et al. (2003) reported that Mcl-1 is a key sensor in controlling protein synthesis and decrease of its proteins is essential to induce apoptosis. They also found that removal of Mcl-1 throughout apoptosis by UC is due to a defect in protein synthesis rather than decrease in its gene expression [24]. Iglesias Sert et al. (2003) showed that after treating Jurkat cells, Mcl-1 protein was degraded by two normal apoptosis stimulation (aspirin and strasporine), while Bcl-2 practically remained unchanged throughout apoptosis process [27]. However, our results showed that Mcl-1 gene expression remained unchanged and $\mathrm{Bcl}-2$ decreased considerably. One probable reason of the inconsistency can be difference in apoptosis patterns induced by different drugs on different cells.

Anti-apoptotic proteins with short half-life such as Mcl-1 are key intermediators of apoptosis as they rapid decrease by translation suppression [28]. Along with supporting the findings about stability of Mcl-1 mRNA level during apoptosis, the results also highlighted importance of translation control of the protein. That is, suppression at transcription level is not a general phenomenon in apoptosis. In fact, apoptosis is not always featured with changes at gene expression level and such changes can be at translation level.

Activation of NF-kB signaling pathway by ATRA and activation of JNK with death signal, consequently, is not necessary for differentiation of granulocytes and they lead to aggregation of immature APL cells and development of ATRA [29]. Mathew et al. (2006) showed that arsenic suppresses the apoptotic effect and controls side-effects of aggregation of useful mature cells. To decompose NF-kB (I-kB) suppressor by ATRA, ATO functions as an antagonist and decreases NF-kB activation and expression of downstream genes of this transcription factor [30]. Recently, Momeni et al. (2009) have shown that ATO suppress cellular proliferation and apoptosis through controlling NF-kB [14].

Anti-apoptotic genes are expressed in cancerous genes and the expression level increases along with progress of the disease. In addition, NF-kB, c-myb, and STAT factors remain active, which in turn may stimulate transcription of Bcl-2 and CIAP2 apoptotic suppressors [31-32]. Therefore, continuous activity of NF-kB preserves apoptosis of cells and leads them toward becoming cancerous cells; while the agents that suppress activity of NF-kB or expression of Bcl-2 are good treatment candidate as they can induce apoptosis.

Tonki et al. (2008) followed EILZA protocol and showed that binding activity of transcription factors NF$\mathrm{kB}$ and STAT5 to their binding sequence in DNA decreased considerably following treating mycosis fungoides with ATO $(1 \mu \mathrm{M})$ [28]. NF-kB is the transcription factor of Eukaryote cells that is bounded to a specific decameric sequence (GGG ACT TTC C) on DNA [23]. STATs are very important for regulating Bcl-2 and BCL-XL genes in particular as they have a binding position for STAT5 at regulating region of $\mathrm{Bcl}-2$ gene [34].

Since the anti-apoptotic gene Bcl-2 is a key gene of transcription factors downstream NF-kB and STAT5, the results in this paper are consistent with those of [34] so that the main reason of decrease in expression of $\mathrm{Bcl}-2$ gene in ATO-induced apoptosis was decrease in NF-kB and STAT5's binding to promoter of the gene, which was due to the effect of arsenic, suppression of transcription and expression of Bcl-2 gene.

As shown by the results and the literature review, ATO is featured with several function mechanisms and pathways. The pathway under focus in this paper was apoptosis inducing mitochondria pathway and as shown, by suppression expression of anti-apoptotic genes, arsenic triggered apoptosis.

Given that initiation of apoptosis entails with activation of caspase 3 and decrease in Mcl-1 and that Real-time PCR showed no changes in expression of them, Real-time method is not enough to examine the effect of these genes on apoptosis. Future works can use Western Blotting method along with Real-time to analyze changes in the protein. Arsenic trioxide is used in Iran and some other countries as preliminary treatment for newly diagnosed APL patients; however, the extent of its effectiveness on the APL patients who have had no treatment beforehand is not clear [12-35, 36]. In light of this, future studies on the exact mechanism of this medicine of influencing cellular cycle and transcription can be helpful for optimizing therapeutic effects and attenuate toxicity and the sideeffects. 


\section{Acknowledgements}

This article is part of thesis work of MSc student Maede Sharifizadeh. The study used financial and laboratory support of Blood, Oncology, and Bone Marrow Research Center of Dr. Shahriaty Hospital, Tehran. The authors wish to thank all the officials and personnel of the center.

\section{References}

1- Lo Coco F, Ammatuna E, Sanz MA. Current treatment of acute promyelocytic leukemia. Haematologica 2007; 92(3): 289-91.

2- Randolph TR. Acute promyelocytic leukemia (AMLM3)-- Part 1: Pathophysiology, clinical diagnosis, and differentiation therapy. Clin Lab Sci 2000; 13(2): 98- 105.

3- de Thé H, Chomienne C, Lanotte M, Degos L, Dejean A. The $\mathrm{t}(15 ; 17)$ translocation of acute promyelocytic leukaemia fuses the retinoic acid receptor alpha gene to a novel transcribed locus. Nature 1990; 347(6293): 558-61.

4- Salomoni P, Pandolfi PP. The role of PML in tumor suppression. Cell 2002; 108(2): 165-70.

5- Lo-Coco F, Ammatuna E. The biology of acute promyelocytic leukemia and its impact on diagnosis and treatment. Hematology Am Soc Hematol Educ Program 2006: 156-61.

6- Ziaei JE. High frequency of acute promyelocytic leukemia in northwest Iran. Asian Pac J Cancer Prev 2004; 5(2): 188-9.

7- Mele A, Stazi MA, Pulsoni A, Visani G, Monarca B, Castelli $\mathrm{G}$, et al. Epidemiology of acute promyelocytic leukemia. Haematologica 1995; 80(5): 405-8.

8- Sell S. Stem cell origin of cancer and differentiation therapy. Crit Rev Oncol Hematol 2004; 51(1): 1-28.

9- Soignet SL, Maslak P, Wang ZG, Jhanwar S, Calleja E, Dardashti LJ, et al. Complete remission after treatment of acute promyelocytic leukemia with arsenic trioxide. $\mathrm{N}$ Engl J Med 1998; 339(19): 1341-8.

10- Tallman MS. Treatment of relapsed or refractory acutepromyelocytic leukemia. Best Pract Res Clin Haematol 2007; 20(1): 57-65.

11- Wang ZY, Chen Z. Acute promyelocytic leukemia: from highly fatal to highly curable. Blood 2008; 111(5): 2505-15.

12- Mathews V, George B, Lakshmi KM, Viswabandya A, Bajel A, Balasubramanian P, et al. Single-agent arsenic trioxide in the treatment of newly diagnosed acute promyelocytic leukemia: durable remissions with minimal toxicity. Blood 2006; 107(7): 2627-32.

13- Shen ZX, Chen GQ, Ni JH, Li XS, Xiong SM, Qiu QY, et al. Use of arsenic trioxide (As2O3) in the treatment of acute promyelocytic leukemia (APL): II. Clinical efficacy and pharmacokinetics in relapsed patients. Blood 1997; 89(9): 3354-60.

14- Momeny M, Zakidizaji M, Ghasemi R, Dehpour AR, Rahimi Balaei M, Abdolazimi Y, et al. Arsenic trioxide induces apoptosis in NB-4, an acute promyelocytic leukemia cell line, through up-regulation of $\mathrm{p} 73$ via suppression of nuclear factor kappa B-mediatedinhibition of p73 transcription and prevention of NFkappaB- mediated induction of XIAP, cIAP2, BCLX( L) and survivin. Med Oncol 2009. [Epub ahead of print]

15- Zhu J, Chen Z, Lallemand-Breitenbach V, de Thé H. How acute promyelocytic leukaemia revived arsenic. Nat Rev Cancer 2002; 2(9): 705-13.

16- Li X, Ding X, Adrian TE. Arsenic trioxide causes redistribution of cell cycle, caspase activation, and GADD expression in human colonic, breast, and pancreatic cancer cells. Cancer Invest $2004 ; 22$ (3) : 389-400.

17- Diaz Z, Colombo M, Mann KK, Su H, Smith KN, Bohle DS, et al. Trolox selectively enhances arsenicmediated oxidative stress and apoptosis in APL and other malignant cell lines. Blood 2005; 105(3): 1237- 45.

18- Ho SY, Chen WC, Chiu HW, Lai CS, Guo HR, Wang YJ. Combination treatment with arsenic trioxide and irradiation enhances apoptotic effects in U937 cells through increased mitotic arrest and ROS generation. Chem Biol Interact 2009; 179(2-3): 304-13.

19- Tallman MS. The expanding role of arsenic in acute promyelocytic leukemia. Semin Hematol 2008; 45(3 Suppl 2): S25-9.

20- Kantarjian H, O'Brien S, Cortes J, Wierda W, Faderl S, Garcia-Manero G, et al. Therapeutic advances in leukemia and myelodysplastic syndrome over the past 40 years. Cancer 2008; 113(7 Suppl): 1933-52.

21- Slack JL, Waxman S, Tricot G, Tallman MS, Bloomfield $\mathrm{CD}$. Advances in the management of acute promyelocytic leukemia and other hematologic malignancies with arsenic trioxide. Oncologist 2002; 7 Suppl 1: 1-13.

22- Li J, Chen P, Sinogeeva N, Gorospe M, Wersto RP, Chrest FJ, et al. Arsenic trioxide promotes histone H3 phosphoacetylation at the chromatin of CASPASE-10 in acute promyelocytic leukemia cells. J Biol Chem 2002; 277(51): 49504-10.

23- Park JW, Choi YJ, Jang MA, Baek SH, Lim JH, Passaniti $\mathrm{T}$, et al. Arsenic trioxide induces $\mathrm{G} 2 / \mathrm{M}$ growth arrest and apoptosis after caspase-3 activation and bcl-2 phosphorylation in promonocytic U937 cells. Biochem Biophys Res Commun 2001; 286(4): 726-34.

24- Zhu J, Okumura H, Ohtake S, Nakamura S, Nakao S. The molecular mechanism of arsenic trioxide-induced apoptosis and oncosis in leukemia/lymphoma cell lines. Acta Haematol $2003 ; 110(1): 1-10$.

25- Danial NN. BCL-2 family proteins: critical checkpoints of apoptotic cell death. Clin Cancer Res 2007; 13(24): 7254-63.

26- Nijhawan D, Fang M, Traer E, Zhong Q, Gao W, Du F, et al. Elimination of Mcl-1 is required for the initiation of apoptosis following ultraviolet irradiation. Genes Dev 2003; 17(12): 1475-86.

27- Iglesias-Serret D, Piqué M, Gil J, Pons G, López JM. Transcriptional and translational control of Mcl-1 during apoptosis. Arch Biochem Biophys 2003; 417(2): 141-52.

28- Tóthová E, Fricova M, Stecová N, Kafková A, Elbertová A. High expression of $\mathrm{Bcl}-2$ protein in acute myeloid leukemia cells is associated with poor response to chemotherapy. Neoplasma 2002; 49(3): 141-4.

29- Mathieu J, Giraudier S, Lanotte M, Besançon F. Retinoidinduced activation of NF-kappaB in APL cells is not essential for granulocytic differentiation, but prolongs the life span of mature cells. Oncogene 2005; 24(48): 7145-55.

30- Tun-Kyi A, Qin JZ, Oberholzer PA, Navarini AA, Hassel JC, Dummer R, et al. Arsenic trioxide downregulates antiapoptotic genes and induces cell death in mycosis fungoides tumors in a mouse model. Ann Oncol 2008; 19 (8): 1488-94.

31- Chu ZL, McKinsey TA, Liu L, Gentry JJ, Malim MH, Ballard DW. Suppression of tumor necrosis factorinduced cell death by inhibitor of apoptosis c-IAP2 is under NF-kappaB control. Proc Natl Acad Sci U S A 1997; 94(19): 10057-62.

32- Mathieu J, Besançon F. Arsenic trioxide represses NFkappaB activation and increases apoptosis in ATRAtreated APL cells. Ann N Y Acad Sci 2006; 1090: 203- 8.

33- Weber-Nordt RM, Egen C, Wehinger J, Ludwig W, 
Gouilleux-Gruart V, Mertelsmann R, et al. Constitutive activation of STAT proteins in primary lymphoid and myeloid leukemia cells and in Epstein-Barr virus (EBV)related lymphoma cell lines. Blood 1996; 88(3): 809-16.

34- Michel L, Dupuy A, Jean-Louis F, Sors A, Poupon J, Viguier $\mathrm{M}$, et al. Arsenic trioxide induces apoptosis of cutaneous $\mathrm{T}$ cell lymphoma cells: evidence for a partially caspaseindependent pathway and potentiation by ascorbic acid (vitamin C). J Invest Dermatol 2003; 121(4): 881-93.

35- Ghavamzadeh A, Alimoghaddam K, Ghaffari SH, Rostami S, Jahani M, Hosseini R, et al. Treatment of acute promyelocytic leukemia with arsenic trioxide without ATRA and/or chemotherapy. Ann Oncol 2006; 17(1): 131-4.

36- Miguel AS. Treatment of Acute Promyelocytic Leukemia. Hematology 2006; (1): 147-155.

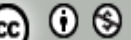

This work is licensed under a Creative Commons AttributionNon Commercial 4.0 International License. 